\title{
Prolongation of the oestrous cycle in cows and ewes after passive immunization with PGF antibodies
}

\author{
R. J. Fairclough, J. F. Smith and L. T. McGowan \\ Ministry of Agriculture and Fisheries, Ruakura Animal Research Station, Private Bag, \\ Hamilton, New Zealand
}

\begin{abstract}
Summary. Three cows and 2 sheep were passively immunized against prostaglandin (PG) F on Day 16 and Days 13-15 of the oestrous cycle respectively. The PGF antiplasma was raised in ovariectomized ewes against a PGF-2 $\alpha$-bovine serum albumin complex and showed $100 \%, 12.5 \%, 0.3 \%,<0.05 \%$ and $<0.01 \%$ cross-reactivity with PGF-2 $\alpha$, PGE-2, PGA-2, PGB-2 and arachidonic acid, respectively. Control animals were given an equivalent amount of ovariectomized ewe plasma. In all passively immunized animals there was evidence of a persistent corpus luteum as indicated by plasma progesterone concentrations and the failure of the animals to return to oestrus until at least 29 days after treatment. These data are consistent with previous proposals that PGF- $2 \alpha$ is the uterine luteolytic factor in sheep and cattle.
\end{abstract}

\section{Introduction}

Infusions of physiological amounts of prostaglandin (PG) $\mathrm{F}$ into the uterine vein of intact ewes (Thorburn \& Nicol, 1971) or into the ovarian artery of ewes with autotransplanted ovaries (McCracken, Glen \& Scaramuzzi, 1970; Barrett et al., 1971) at mid-cycle results in the premature regression of the corpus luteum $(\mathrm{CL})$. These observations, when combined with other data including the finding of intermittent secretion of PGF from the uterus of ewes concomitant with the decline in plasma progesterone levels at luteolysis (Thorburn, Cox, Currie, Restall \& Schneider, 1973), have provided good evidence that PGF is the uterine luteolytic factor in ewes (see reviews by Flint \& Hillier, 1975; Baird, 1977). There is, however, some debate over whether PGF is the uterine luteolytic factor in the cow. Surges in the plasma concentrations of PGF have been detected in utero-ovarian blood of cows during the period of luteal regression (Nancarrow et al., 1973) and peaks of the PGF metabolite 13,14-dihydro-15-keto-prostaglandin F (PGFM) have been noted in jugular plasma concomitant with luteolysis (Peterson, Fairclough, Payne \& Smith, 1975; Kindahl, Edqvist, Bane \& Granstrom, 1976). In addition, physiological infusions of PGF-2 $\alpha$ into the uterine vein of cows during the mid-luteal phase of the cycle result in a rapid and precipitous decline in plasma progesterone concentrations (Goding et al., 1971-72). In an attempt to obtain further evidence that PGF-2 $\alpha$ is the luteolytic factor in the cow Hansel, Shemesh, Hixon \& Lukaszewska (1975) searched for luteolytic activity in endometrium samples of cows around oestrus but found little activity in the fraction containing PGF-2 $\alpha$. Arachidonic acid, on the other hand, was active in the bioassay used to locate the luteolysin and it was present in high concentrations in endometrial tissue. In another study, Shemesh \& Hansel (1975) showed elevated concentrations of PGF- $2 \alpha$ in endometrial tissue and utero-ovarian plasma but no corresponding change in ovarian arterial plasma of cows around the time of expected luteolysis. Hansel et al. (1975) concluded from these data that PGF-2 $\alpha$ may not be the uterine luteolysin in the cow. 
In view of these conflicting reports we passively immunized cows with PGF antibodies during the late luteal phase of the cycle to determine whether there was a relationship between PGF and luteal regression in this species. Ewes were also immunized against PGF to obtain further evidence that PGF is involved in ovine luteolysis.

\section{Materials and Methods}

\section{Preparation of PGF antibodies}

Prostaglandin F-2 $\alpha$ was conjugated to bovine serum albumin (BSA) by a modification of the method described by Erlanger, Borek, Beiser \& Leiberman (1958).

The PGF-2 $\alpha$ (27 mg THAM salt, Upjohn Chemical Co., Kalamazoo, Michigan, U.S.A.) was dissolved in $0.1 \mathrm{ml} \mathrm{H} \mathrm{H}_{2} \mathrm{O}, 0.5 \mathrm{ml}$ dioxan and $20 \mu \mathrm{l}$ tributylamine. The solution was cooled to $11^{\circ} \mathrm{C}, 10 \mu \mathrm{l}$ isobutylchloroformate were added and the contents were cooled at $11^{\circ} \mathrm{C}$ for 30 min. This mixture was added to a solution containing $60 \mathrm{mg}$ BSA dissolved in $1.0 \mathrm{ml}$ water and $1.2 \mathrm{ml}$ dioxan. After mixing, $1 \mathrm{~N}-\mathrm{NaOH}(40 \mu \mathrm{l})$ was added, and the reaction was allowed to proceed for $4 \mathrm{~h}$ at $4^{\circ} \mathrm{C}$. The solution was dialysed against 3 changes of distilled water ( 2 litres each) over $24 \mathrm{~h}$ and the PGF-2 $\alpha$ conjugate was then freeze-dried and stored at $-20^{\circ} \mathrm{C}$.

Antibodies against PGF-2 $\alpha$ were prepared by emulsifying $3 \mathrm{mg}$ of the PGF-BSA conjugate dissolved in $3 \mathrm{ml}$ saline $(9 \mathrm{~g} \mathrm{NaCl} / 1)$ with an equal volume of Freund's complete adjuvant. This mixture $(2 \mathrm{ml})$ was then injected into 6 subcutaneous sites of an ovariectomized ewe. Booster injections were given every 2 weeks for 6 weeks then at monthly intervals. The antiplasma used in this study was obtained 90 days after the primary injection. Blood was collected into a heparinized container and centrifuged at $4^{\circ} \mathrm{C}$ within $30 \mathrm{~min}$. The titre of this antiplasma, defined as the dilution of plasma required to give $50 \%$ binding of tritiated PGF-2 $\alpha$, was $1: 4500$. The cross-reactions of the antiplasma were $12.5,0.3$ and $<0.05 \%$ with prostaglandins of the $\mathrm{E}-2$, A-2 and B-2 series respectively and $<0.01 \%$ with arachidonic acid.

\section{Sheep}

Four ewes with normal cycle lengths ( $17 \pm 0.5$ days) were selected from a flock of ewes treated with intravaginal sponges containing 6a-methyl-17 $\alpha$-hydroxyprogesterone acetate (Upjohn Chemical Co.) to synchronize oestrus and left to complete one cycle. Prostaglandin F antiplasma was infused into the jugular vein of Ewes 137 and 166 on Days 13 (70 ml), 14 (20 $\mathrm{ml})$ and $15(10 \mathrm{ml})$ of the subsequent cycle. The same volumes of plasma from an ovariectomized ewe were given to 2 control ewes (Nos 162 and 189) on the same day. A harnessed vasectomized ram was run with the ewes to detect behavioural oestrus and observations were made twice daily. Blood $(10 \mathrm{ml})$ was withdrawn from indwelling jugular catheters once daily from Days 6 to 12 of the cycle, twice daily from Days 13 to 17 and then once daily again for 6 days. The jugular vein used was not that used to infuse the PGF antiplasma. In addition, weekly samples were collected from two of the passively immunized ewes for a further 6 weeks. The blood was collected into ice-cold heparinized syringes, centrifuged within $10 \mathrm{~min}$ and the plasma stored at $-15^{\circ} \mathrm{C}$ until analysis. The ovaries and uterus were examined via a mid-ventral laparotomy 10 (4 ewes), 31 ( 2 ewes), 72 ( 2 ewes) and 130 ( 1 ewe) days after the start of treatment (Day 13). Once a ewe had ovulated it was not examined further.

\section{Cows}

Five multiparous Friesian cows which showed regular cyclic activity before the trial were used. Oestrus was synchronized by means of progestagen-impregnated sponges as described by 
Smith (1974). On Day 16 of the second oestrous cycle after sponge withdrawal 3 of the cows were injected i.v. with $100 \mathrm{ml}$ PGF antiplasma. Two control cows were injected with similar volumes of ovariectomized ewe plasma. Blood samples were collected from the jugular vein of all cows once daily from Days 6 to 16 of the oestrous cycle, and then twice daily for up to 8 days. In addition, samples were obtained from the 3 immunized cows every 2-3 days for the next 10 weeks. Examination of the ovaries and the uterus was carried out via rectal palpation 10, 16, 25, 54 and 73 days after the start of treatment. Control cows were palpated 10 and 16 days after treatment. A vasectomized bull fitted with a chin-ball harness was used to detect behavioural oestrus.

\section{Radioimmunoassay of progesterone}

The method used to measure plasma progesterone concentrations was that described by Fairclough, Hunter \& Welch (1975). Plasma samples were extracted in duplicate with 4 volumes of hexane and progesterone concentrations were measured by radioimmunoassay using polyethylene glycol to separate free and bound steroid. The antiserum used was raised in sheep against a progesterone-11-BSA conjugate, the cross-reactions were $4 \cdot 2,0 \cdot 6$, and $1 \%$ with $20 \beta$-hydroxypregn-4-ene-3-one, 20 $\alpha$-hydroxypregn-4-ene-3-one and 17 $\alpha$-hydroxyprogesterone, respectively, and $<0.1 \%$ with all other steroids tested. The smallest amount of progesterone which could be measured with precision was $0.15 \mathrm{ng} / \mathrm{ml}$ plasma. The intra- and inter-assay coefficients of variation for a plasma pool assayed on 16 consecutive occasions and containing progesterone at a concentration of $0.9 \mathrm{ng} / \mathrm{ml}$ were $9.6 \%$ and $10.9 \%$, respectively.

\section{Results}

Ewes

The progesterone values in the control ewes (Nos 162 and 189) declined from 1-3 ng/ml to $<0.5 \mathrm{ng} / \mathrm{ml}$ between Days 13 and 16 of the cycle. These ewes displayed oestrus on Days 17 and 18 of the cycle and subsequently ovulated as indicated by the presence of newly formed CL
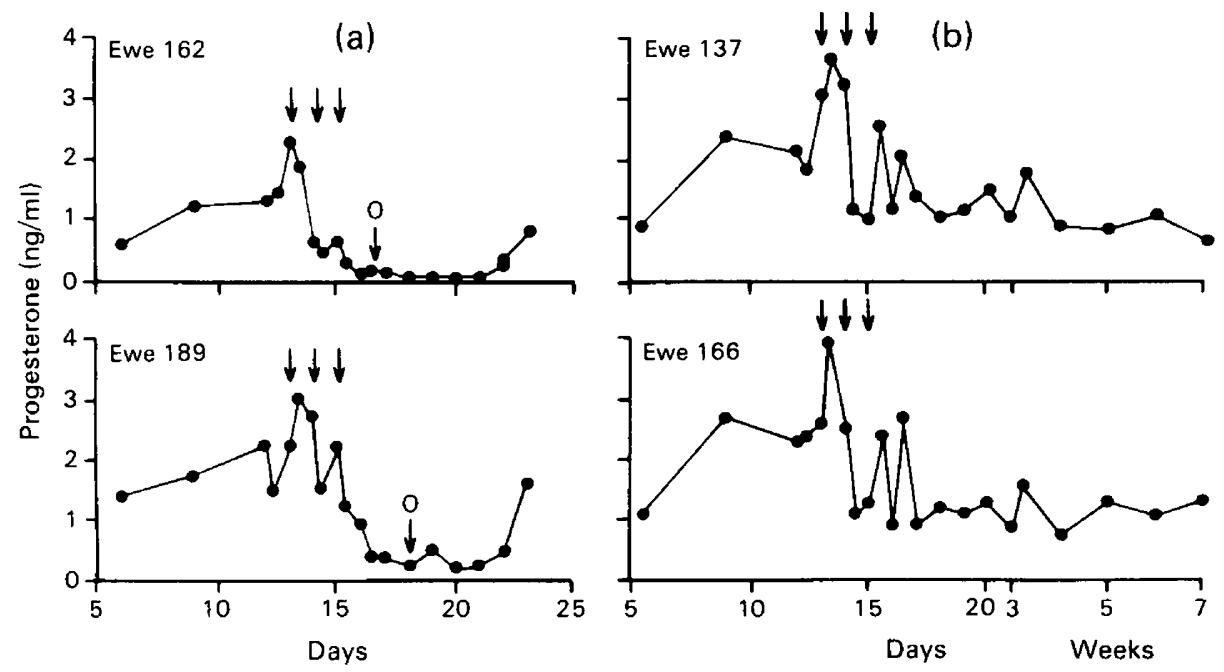

Time from previous oestrus

Text-fig. 1. Plasma concentrations of progesterone in (a) Ewes 162 and 189 (controls) and (b) Ewes 137 and 166 (passively immunized against prostaglandin F). The arrows indicate the times of injection of plasma from an ovariectomized ewe or of antiplasma to prostaglandin $\mathrm{F}$. O denotes behavioural oestrus. 
at laparotomy 10 days after treatment and a rise in plasma progesterone concentrations 5 and 6 days after oestrus (Text-fig. 1). The plasma progesterone levels in the passively immunized ewes (Nos 137 and 166) did not fall to low levels $(<0.5 \mathrm{ng} / \mathrm{ml})$ until at least 38 days after the start of treatment (Text-fig. 1). These ewes failed to display oestrus at the expected time. Laparotomy 10 and 31 days after the start of the treatment revealed the presence of 2 persistent $C L$ and several small follicles in the ovaries of each of the 2 ewes. The CL were similar in appearance to those found in pregnant ewes. In Ewe 137 the CL had regressed by Day 72 after passive immunization since only corpora albicantia were then present.

The uteri of the passively immunized ewes were considerably distended by fluid in the lumen. This effect was particularly noticeable in Ewe 166 at 72 days after treatment.

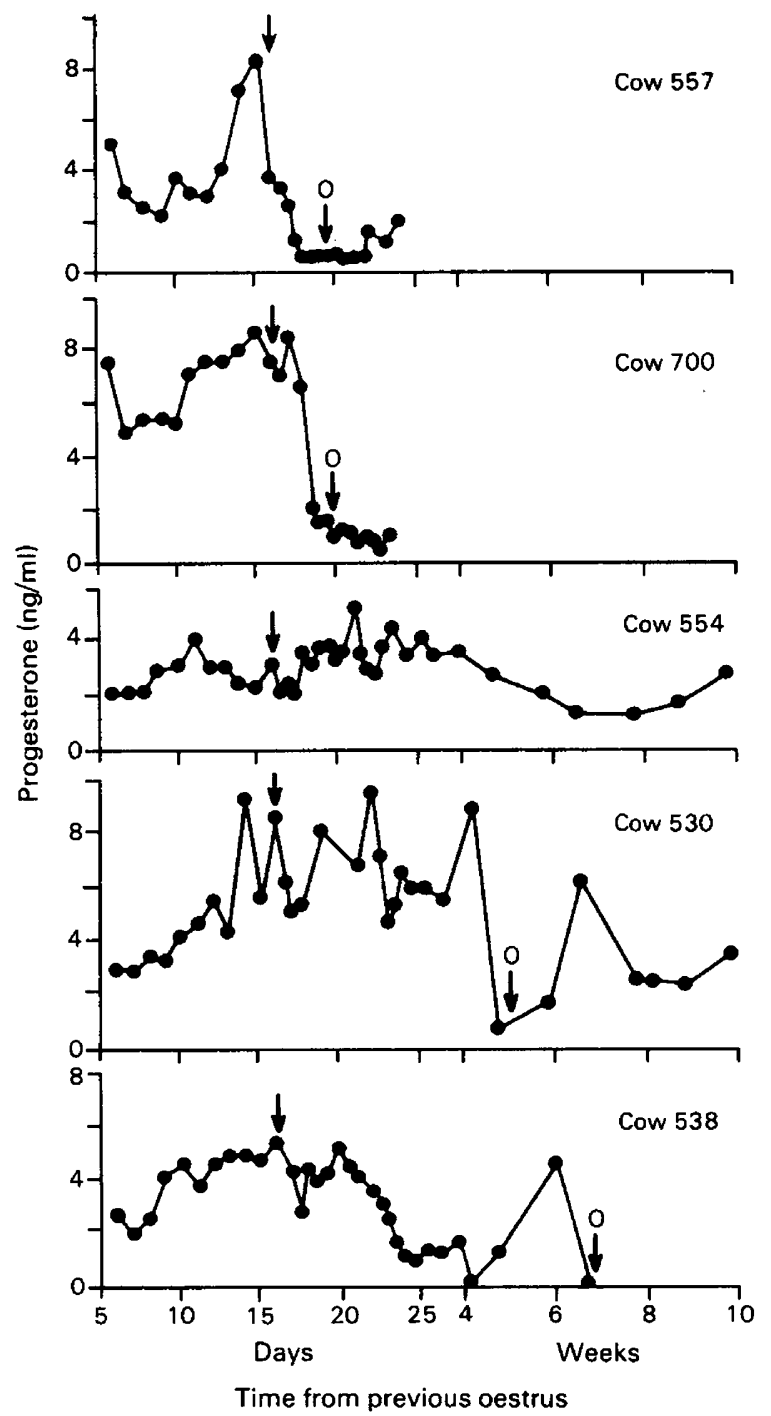

Text-fig. 2. Plasma concentrations of progesterone in Cows 557 and 700 (injected i.v. on Day 16 of the oestrous cycle with plasma from an ovariectomized ewe) and Cows 554, 530 and 538 (injected similarly with antiplasma to prostaglandin $\mathrm{F}$ ). $\mathrm{O}$ denotes behavioural oestrus. 


\section{Cows}

Changes in the plasma concentrations of progesterone in the 3 treated and 2 control cows are illustrated in Text-fig. 2. In the 2 control cows progesterone declined from basal levels of 2-8 to $<1 \mathrm{ng} / \mathrm{ml}$ on Days $17-19$ of the oestrous cycle. These cows showed oestrus on Day 19 and subsequently ovulated; newly formed CL were present in both cows at palpation 7-8 days after oestrus. By contrast, in the 3 passively immunized cows plasma progesterone did not decline at the time of expected luteolysis (Text-fig. 2).

In Cows 530 and 538 the plasma progesterone levels declined to $<1 \mathrm{ng} / \mathrm{ml} 37$ and 29 days respectively after the last observed oestrus. In Cow 350 behavioural oestrus was observed 1 day after the fall in plasma progesterone but for Cow 538 the decline in progesterone was not accompanied by behavioural oestrus. However, since a newly formed CL was detected at palpation 16 days after immunization, it was concluded that ovulation had occurred in Cow 538 but that oestrus was not detected. In Cow 554 there was prolongation of the oestrous cycle for at least 70 days and plasma progesterone concentrations did not fall below $1 \mathrm{ng} / \mathrm{ml}$ over this period. A persistent CL was found at palpation 10,16, 25 and 54 days after treatment. The uterine tracts of the immunized and control cows were examined by rectal palpation and appeared normal throughout the trial.

\section{Discussion}

The present study demonstrates that the life-span of the CL can be prolonged in ewes and cows by administering PGF antibodies during the time of expected luteolysis. The PGF antiplasma used for passive immunization showed low cross-reactivity towards prostaglandins of the $A$ and B series although some displacement of PGF from the antibody was noted for PGE-2. However, since it has been shown that PGE-2 stimulates the production of progesterone in vitro (Henderson \& McNatty, 1975) and antagonizes the action of PGF-2 $\alpha$ in vivo (Henderson, Scaramuzzi \& Baird, 1977), one would expect that the neutralization of PGE-2 would cause a shortening rather than a lengthening of the oestrous cycle. The most reasonable explanation for our results, therefore, is that administered PGF antibodies bind with the endogenous PGF, thus preventing it from reaching its binding site on the membrane of the CL (Rao, 1973; Powell, Hammarstrom \& Samuelsson, 1975).

The results of this study confirm and extend earlier findings of Scaramuzzi \& Baird (1976) who showed a lengthening of the oestrous cycle in sheep after active immunization against PGF-2 $\alpha$. Our results therefore add weight to their suggestion that PGF- $2 \alpha$ is involved in normal luteal regression in ewes. In addition, we have been able to demonstrate that luteolysis can be blocked by passively immunizing ewes against PGF as late as Day 13 of the oestrous cycle. These results, which indicate that the endocrine events which influence $\mathrm{CL}$ regression do not become irreversible until at least Day 13 of the oestrous cycle, are compatible with the observations of Moor, Hay, Short \& Rowson (1970) that luteal involution can be arrested by hysterectomizing sheep on Day 15 of the oestrous cycle.

The large volume of fluid which accumulated in the uterus of 1 of the 2 immunized ewes may be due to prolonged exposure of the uterus to progesterone since it has been shown that excess uterine fluid can be caused by the presence of a persistent CL in ewes with autotransplanted ovaries (Harrison, Heap, Horton \& Poyser, 1972) or by administering progesterone for a prolonged period to anoestrous ewes (Amoroso, Harrison, Heap \& Poyser, 1973).

Our findings for cows are similar to those observed for ewes in that they indicate that luteolysis can be halted by passively immunizing with PGF antiplasma 2-3 days before expected luteolysis. These results suggest that PGF- $2 \alpha$ does play a role in regulating the life-span of the $\mathrm{CL}$ in the cow. Our data do not, however, provide information on the source of PGF-2 $\alpha$ secreted 
during luteolysis. Nevertheless, an increasing amount of data is accumulating which suggests that uterine PGF-2 $\alpha$ is the factor responsible for the regression of CL in the cow. The importance of the uterus in the luteolytic process was demonstrated by Wiltbank \& Casida (1956) when they were able to show the presence of a persistent CL in cows hysterectomized during the mid-luteal phase of the oestrous cycle. More recently, Ginther (1968) showed that the uterus does produce a luteolytic factor which acts locally on the ipsilateral CL. The possibility that this factor was PGF-2 $\alpha$ was deduced from experiments showing that PGF- $2 \alpha$ is luteolytic in cows and from observations showing surges of PGF in uterine venous plasma or its metabolite (PGFM) in jugular plasma of cows coincident with the decline in progesterone levels at luteolysis (Nancarrow et al., 1973; Peterson et al., 1975, Kindahl et al., 1976). This intermittent nature of PGF release may explain why Hansel et al. (1975) failed to detect PGF-2 $\alpha$ in endometrial samples collected from cows between Days 11 and 17 of the oestrous cycle. These endometrial tissues did, however, contain relatively high amounts of arachidonic acid, indicating that this substance could play a role in regulating PGF biosynthesis by controlling the amount of PGF precursor reaching the ovary (Hansel et al., 1975). Our results would tend to argue against this hypothesis since luteolysis was blocked by PGF antibodies which showed very low cross-reactivity with arachidonic acid $(<0.01 \%)$. However, there still remains the possibility that the PGF antibodies could prevent PGF derived from the ovary reaching the CL although a previous report has suggested that PGF antibodies cannot cross cell membranes (Scaramuzzi \& Baird, 1976). Perhaps the best evidence against the proposal that PGF-2 $\alpha$ is produced within the ovary from exogenous arachidonic acid was provided by Lewis \& Warren (1974) when they showed that indomethacin could block oestradiol-17 $\beta$-induced luteolysis if administered into the uterus of heifers between Days 14 and 21 of the oestrous cycle but not when it was given systemically. If it is assumed that oestradiol-17 $\beta$ in these experiments induces luteolysis by a mechanism similar to that which acts during the normal oestrous cycle then these experiments provide strong evidence for the involvement of uterine PGF- $2 \alpha$ in normal CL regression.

The cumulative evidence derived from this and other studies, therefore, is consistent with the proposal advanced by Goding et al. (1971-72) which suggested that PGF-2 $\alpha$ is the uterine luteolytic factor in ewes and cows.

We thank Mrs M. A. Rabjohns for laboratory assistance with the progesterone determinations.

\section{References}

Amoroso, E.C., Harrison, F.S., Heap, R.B. \& Poyser, N.L. (1973) The production of prostaglandin $F_{2 \alpha}$ by the uterus of sheep. J. Endocr. 57, lix.

Baird, D.T. (1977) Local utero-ovarian relationships. In Control of Ovulation, pp. 217-233. Eds D. B. Crighton, G. R. Foxcroft, N. B. Haynes \& G. E. Lamming. Butterworths, London.

Barrett, S., Blockey, M.A. de B., Brown, J.M., Cumming, I.A., Goding, J.R., Mole, B.J. \& Obst, J.M. (1971) Initiation of the oestrous cycle in the ewe by infusions of PGF $_{2 \alpha}$ to the autotransplanted ovary. $J$. Reprod. Fert. 24, 136-137.

Erlanger, B.G., Borek, F., Beiser, S.M. \& Lieberman, S. (1958) Steroid-protein conjugates. J. biol. Chem. 234, 1090-1094.

Fairclough, R.J., Hunter, J.T. \& Welch, R.A.S. (1975) Peripheral plasma progesterone and utero-ovarian prostaglandin $F$ concentrations in the cow around parturition. Prostaglandins 9, 901-914.

Flint, A.P.F. \& Hillier, K. (1975) Prostaglandins and reproductive processes in female sheep and goat. In
Prostaglandins and Reproduction, pp. 271-308. Ed. S. M. M. Karim. MTP Press, Lancaster.

Ginther, O.J. (1968) Utero-ovarian relationships in cattle: physiologic aspects. J. Am. vet med. Ass. 135 , 1656-1664.

Goding, J.R., Cumming, I.A., Chamley, W.A., Brown, J.M., Cain, M.D., Cerini, J.C., Cerini, M.E.D. Findlay, J.K., O'Shea, J.D. \& Pemberton, D.H. (1971/72) Prostaglandin $F_{2 \alpha}$ 'the' luteolysin in the mammal? Gynecol. Invest. 2, 73-97.

Hansel, W., Shemesh, L.M., Hixon, J.E. \& Lukaszewska, J. (1975) Extraction, isolation and identification of a luteolytic substance from bovine endometrium. Biol. Reprod. 13, 30-37.

Harrison, F.A., Heap, R.B., Horton, E.W. \& Poyser, N.L. (1972) Identification of prostaglandin $F_{2 \alpha}$ in uterine fluid from nonpregnant sheep. J. Endocr. $\mathbf{5 3}$, $215-222$.

Henderson, K.M. \& McNatty, K.P. (1975) A biochemical hypothesis to explain the mechanism of luteal regression. Prostaglandins 9, 779-797. 
Henderson, K.M., Scaramuzzi, R.J. \& Baird, D.T. (1977) Simultaneous infusion of prostaglandin $E_{2}$ antagonizes the luteolytic action of prostaglandin $\mathrm{F}_{2 a}$ in vivo. J. Endocr. 72, 379-383.

Kindahl, H., Edqvist, L.E., Bane, A. \& Granstrom, E. (1976) Blood levels of progesterone and 15-keto13,14-dihydro-prostaglandin $\mathrm{F}_{2 \alpha}$ during the normal oestrous cycle and early pregnancy in heifers. Acta endocr., Copenh. 82, 134-149.

Lewis, P.E. \& Warren, J.E. (1974) Indomethacin inhibits estrogen-induced luteolysis in heifers. J. Anim. Sci. 39, 992.

McCracken, J.A., Glen, M.E. \& Scaramuzzi, R.J. (1970) Corpus luteum regression induced by prostaglandin $\mathrm{F}_{2 \alpha}$.J. clin. Endocr. Metab. 30, 544-546.

Moor, R.M., Hay, M.F., Short, R.V. \& Rowson, L.E.A. (1970) The corpus luteum in sheep: effect of uterine removal during luteal regression. J. Reprod. Fert. 21, 319-326.

Nancarrow, C.D., Buckmaster, J., Chamley, W.A., Cox, R.I., Cumming, I.A., Cummins, L., Drinin, J.P., Findlay, J.K., Goding, J.R., Restall, B.J., Schneider, W. \& Thorburn, G.D. (1973) Hormone changes around oestrus in the cow. J. Reprod. Fert. 32, $320-321$.

Peterson, A.J., Fairclough, R.J., Payne, E. \& Smith, J.F. (1975) Hormone changes around bovine luteolysis. Prostaglandins 10, 675-681.
Powell, W.S., Hammarstrom, S. \& Samuelsson, B. (1975) Occurrence and properties of a prostaglandin $\mathrm{F}_{2 \alpha}$ receptor in bovine corpora lutea. Eur. $J$. Biochem. 56, 73-77.

Rao, Ch.V. (1973) Receptors for prostaglandins and gonadotropins in the cell membranes of bovine corpus luteum. Prostaglandins 4, 567-576.

Scaramuzzi, R.J. \& Baird, D.T. (1976) The oestrous cycle of the ewe after active immunization against prostaglandin F-2a. J. Reprod. Fert. 46, 39-47.

Shemesh, M. \& Hansel, W. (1975) Level of prostaglandin $\mathrm{F}$ in bovine endometrium, uterine venous, ovarian arterial and jugular plasma during the oestrous cycie. Proc. Soc. exp. Biol. Med. 148, 123-126.

Smith, J.F. (1974) Synchronization of oestrus in cattle. N.Z. Jl Agric. 129, 26-31.

Thorburn, G.D. \& Nicol, D.H. (1971) Regression of the ovine corpus luteum after infusion of prostaglandin $F_{2 \alpha}$ into the ovarian artery and uterine vein. $J$. Endocr. 51, 785-786.

Thorburn, G.D., Cox, R.I., Currie, W.B., Restall, BJ. \& Schneider, W. (1973) PGF and progesterone concentrations in the utero-ovarian venous plasma of the ewe during the oestrous cycle and early pregnancy. $J$. Reprod. Fert., Suppl. 18, 151-158.

Wiltbank, J.N. \& Casida, L.E. (1956) Alteration of ovarian activity by hysterectomy. J. Anim. Sci. 15, 134-140.

Received 16 September 1980 